\title{
Fragment Reattachment -A Simple Technique to Restore Coronal Fracture
}

\author{
Ahmed Mohammed Hassan Altabbakh \\ Department of Restorative Dental Sciences, Saudi Arabia.
}

Submission: December 13, 2016; Published: January 12, 2017

*Corresponding author: Ahmed Mohammed Hassan Altabbakh, DDS, MSc, PhD, Assissstant professor, Department of Restorative Dental Sciences, Al-Farabi colleges for dentistry and nursing, Riyadh 11691, P.0.Box 85184, Saudi Arabia, Tel: 00966-1227315; Fax: +966 1 2324580; Mobile: +966561260574; Email: ahmed.altabbakh@alfarabi.edu.sa

\begin{abstract}
Coronal fracture of anterior teeth is a common problem of children as a result of dental trauma particularly during sports. This fracture has its drawbacks on the smile appearance that may affect the psychic state of the child. Restoration of such fracture is very important to restore the esthetic of the smile. May techniques are available; the most conservative one is reattachment of the fractured piece. This article describes the reattachment of fractured fragment of left central incisor of a child. The fractured tooth fragment was successfully reattached using a very simple technique. Circumferential beveling and using of micro hybrid composite was sufficient to get a good esthetic and durable result. At the end of the treatment, the patient was very happy and satisfied.
\end{abstract}

Keywords: Reattachment; Bonding; Coronal fracture

\section{Introduction}

Dental trauma accounts for $17.5 \%$ of children and adolescent under 18 years old. This percentage may differ from country to another depending on many factors such as economic condition and sport activities. Among different causes of dental trauma, failing is the most important one resulting in enamel fracture [1]. Usually males are subjected to dental trauma more frequently than females as they perform more activities such as bicycle riding, sports, fighting [2]. Dental trauma often affects patient socially and psychologically, so it is of a great importance to the clinician to manage the psyาchological impact as well as the physical injury of the partient $[3,4]$. As a result restoring a patient's lost natural smile becomes an important topic of today's dentistry [5].

The continuous improvements in materials and fabrication techniques provide dentists nowadays with multiple choices for treatment options with better prognosis [6]. Unfortunately ceramics and composites have a different surface texture than that of the tooth and this leads in a different light reflection at the surface. So, the use of these materials is not the first choice in restoring fractured anterior teeth in case of presence of the fractured segment [7]. As result of development in adhesive materials, reattachment of the dislocated fragment of fractured tooth becomes acceptable treatment. Tooth fragment reattachment has many advantages. These advantages include: time saving, less expensive, and more conservative [8].

\section{Case Report}

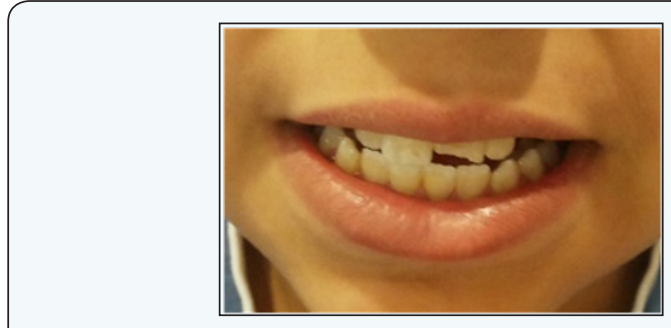

Figure 1: Preoperative extra-oral frontal view.

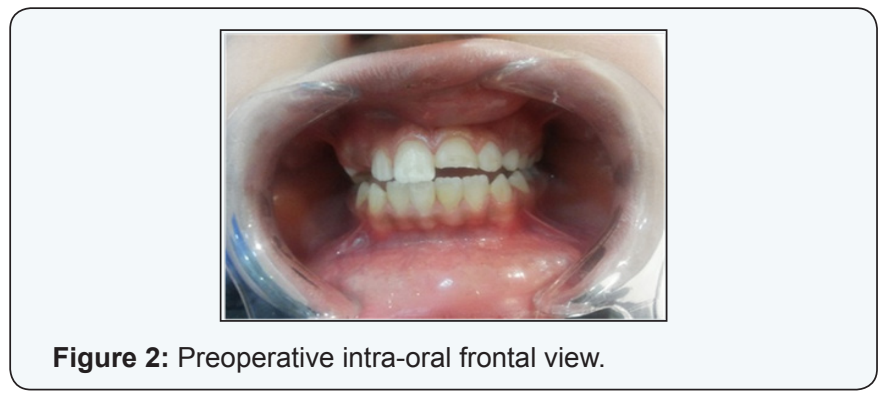

A 12 years old male patient came to the clinic at Alfarabi Dental Collage, department of restorative dental science with his mother with a fractured upper left central incisor. This fractured has occurred one day ago (Figure 1,2). Clinical examination revealed no pulp exposure. The fracture was confined to enamel 
and dentin (Ellis class II). There was a horizontal fracture separating the incisal third of the tooth from the remaining two thirds. The gingival and supporting tissue of the tooth were healthy with no signs of tearing or inflammation. The tooth responded normally to thermal pulp testing, and there was no pain on percussion. The chief complaint of the patient was the bad esthetics. He was in good general health and doesn't have allergies to medications. His oral hygiene performance was satisfactory and flossing was also applied. He brought the fractured piece in normal saline. Periapical radiograph was taken to examine the root and supporting bone. The radiograph showed neither root not supporting alveolar bone was fractured. There was no periapical radiolucency.

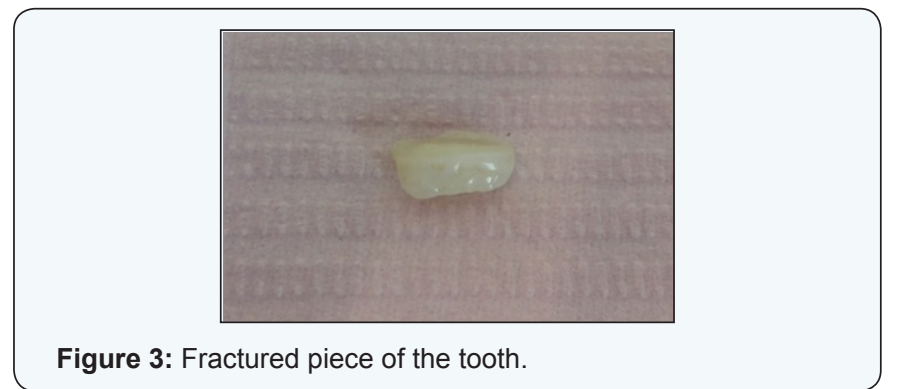

First, the fractured fragment was cleaned carefully with $0.2 \%$ chlorhexidine. The fractured fragment (Figure 3) was then approximated carefully to the fractured site to insure there is no last piece. The fragment fit perfectly and the fracture line acted as a guide to replace it in the normal relation with the remaining tooth portion. Shade selection was done at this stage using vita classic shade guide. The shade was A3.Then, the fractured fragment was beveled circumferentially with a tapered diamond (Swhite burs, Italy), and then etched with 35\% phosphoric acid (Condicionador, Dentsply, Brazil) for 15 seconds and washed using air-water spray till all enchant jell was removed. The fragment was then dried with indirect gentle air spray for 5 seconds, leaving the surface slightly moist.

The tooth was cleaned and polished using prophylactic past, and then rubber dam was applied. A circumferential beveling and acid etching was performed for the tooth as described for the fracture fragment. A single coat of bonding agent (Prime \& Bond 2.1, Dentsply, Brazil) was applied on the beveled surfaces of both the fracture fragment and the tooth, and then a gentle air spray was applied indirectly to the surfaces for 5 seconds to allow for evaporation of solvent and then cured for 20 seconds using (Cromalux-E mega-physics dental Rastatt; Germany). A small piece of microhybrid composite (TPH, Dentsply, Brazil) was then applied on the fractured fragment. The fracture fragment was then approximated immediately and carefully to the fractured site and cured for 20 seconds from both buccal and palatal sides. The excess composite was projected and slightly overfilled the space created by approximation of the two bevels together (Figure 4). The excess composite was removed, finished, and polished (Figure 5) using Sof-Lex system (3M ESPE, USA). The occlusion was checked in all excursive movements to avoid any undue forces on the newly bonded fractured piece. At the end of treatment the demarcation line between the fractured piece and the tooth was unnoticed and the tooth appeared normal (Figure $6)$.

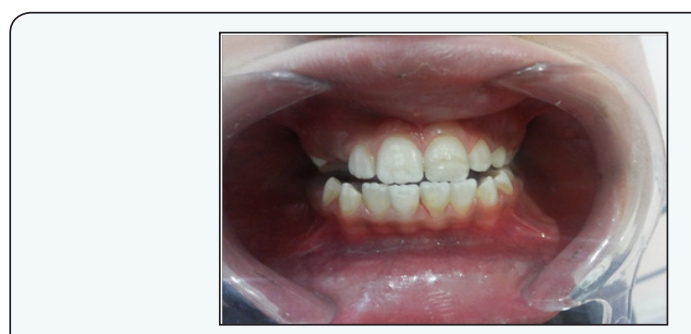

Figure 4: Assembled fracture with protruding excess composite.
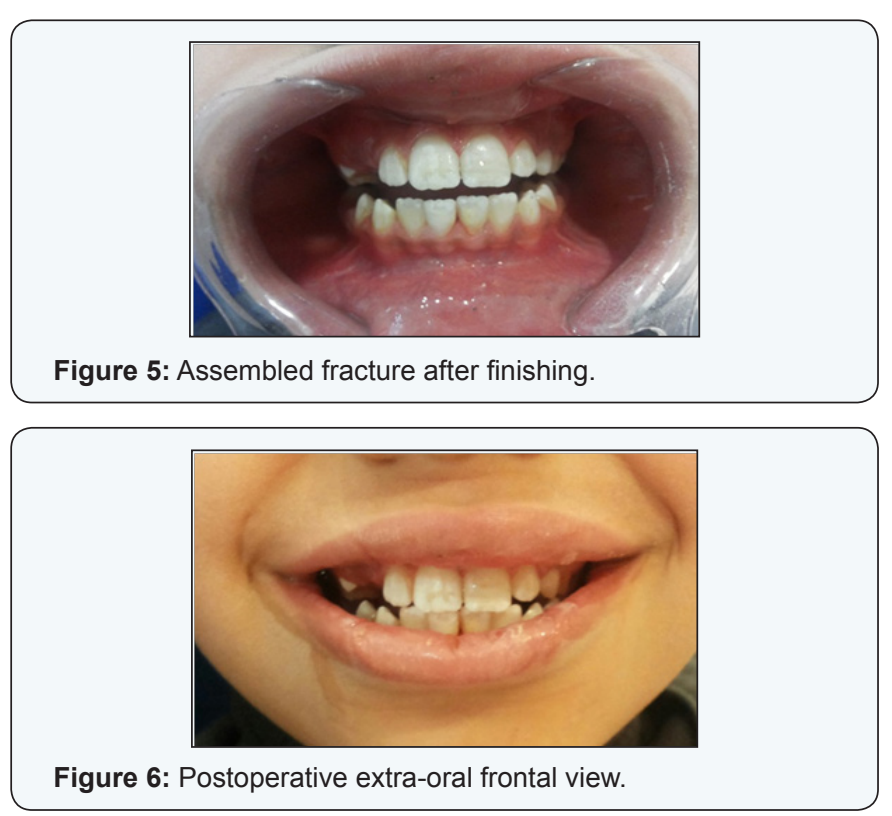

\section{Discussion}

The technique used in this case is a very simple, non complicated technique. Whenever the fractured fragment is available intact, the reattachment treatment has to be the most desired treatment. This allows for conservative, simple and esthetic treatment option [4,9]. However, the availability of the fractured fragment is not the only indicator for reattachment treatment with good prognosis [10]. Many factors will affect the success of reattachment. These factors include: the site and size of the fracture, the condition of periodontium and pulp, the occlusion and the time elapsed after trauma [11]. Fragment reattachment to the fractured tooth results in good and longlasting aesthetics because it restores the tooth's original anatomic form, color and surface texture. It can restore function, can result in a positive psychological response and is a reasonably simple procedure [3].

Various clinicians have used a different bevel designs, chamfers, dentinal and enamel grooves for the reattachment of tooth fragments [10]. The technique used in this case was a reasonable simple maintaining a complete dry field with 
complete adherence to the manufactures' instructions when using the restorative materials. In this case we use circumferential bevel to increase the surface area available for bonding, and to mask the fracture line demarcated the fractured fragment from the remaining tooth structure. Also circumferential bevel lead to increase the bond strength of the fracture fragment to the remaining tooth [12].

As the fracture resulted from failing of the patient during playing football it is desirable to wear mouth guard to provide protection to the teeth while playing. Different types of mouth guards are available and provide a sufficient level of protection. This is in accordance with the American Dental Association recommends the use of mouth guards in 29 sports/ exercise activities [13]. Fracture fragment reattachment has many advantages over the use direct or indirect esthetic restorative materials. These advantages include; the exact shade and contour, opalescence, and the texture [14].

\section{Conclusion}

The available restorative material and bonding systems with careful and simple technique allow for reattachment of the fracture segment with good result. This technique seems to be a conservative one with good esthetic result. The technique used in this case is simple and time saving to restore a fracture tooth. It emphasizes the possibility of using the fractured segment of the tooth, rather than the use of restorative material and adds a spotlight.

\section{References}

1. Azami-Aghdash S, Ebadifard Azar F, Pournaghi Azar F, Rezapour A, Moradi Joo M, et al. (2015) Prevalence, etiology, and types of dental trauma in children and adolescents: systematic review and metaanalysis. Med J Islam Repub Iran 29(4): 234.

2. Rocha MJ, Cardoso M (2001) Traumatized permanent teeth in Brazilian children assisted at the Federal University of Santa Catarina, Brazil. Dent Traumatol 17(6): 245-249.
3. Venugopal L, Lakshmi M, Babu D, Kiran V (2014) Comparative evaluation of impact strength of fragment bonded teeth and intact teeth: An in vito study. J Int Oral Health 6(3): 73-76.

4. Jagannath-Trovi S, Kala M (2014) Restore the natural - A review and case series report on reattachment. J ClinExp Dent 6(5): e595-598.

5. Gargari M, Ceruso FM, Pujia A, Prete V (2014) Restoration of anterior teeth using an indirect composite technique. Case report. Oral Implantol (Rome) 6(4): 99-102.

6. Magne P, Belser UC (2004) Novel porcelain laminate preparation approach driven by a diagnostic mock-up. J EsthetRestor Dent 16(1): 7-18.

7. Farronato D, Mangano F, Pieroni S, Lo Giudice G, Briguglio R, (2012) Esthetic integration between ceramic veneers and composite restorations: a case report. Ann Stomatol (Roma) 3(3-4): 132-137.

8. Abdulkhayum A, Munjal S, Babji P, Chaurasia V, Munjal S, et al. (2014) In-vito evaluation of fractured strength recovery of reattached anterior fractured tooth fragment using different re-attachment techniques. J ClinDiagn Res 8(3): 208-211.

9. Sargod S, Baht S (2010) A 9 year follow-up of fractured tooth fragment reattachment. Contemp Clin Dent 1(4): 243-245.

10. Hiremath H, Kulkarni S, Saikalyan S, Chordhiya R (2012) Use of ribbond and panavia $\mathrm{F}$ cement in reattaching fractured tooth fragment of vital maxillary anterior teeth. Contemp Clin Dent 3(4): 478-480.

11. Choudhary A, Garg R, Bhalla A, Khatri RK (2015) Tooth fragment reattachment: An esthetic, biological restoration. J Nat SciBiol Med 6: 205-207.

12. Chazine M, Sedda M, Ounsi H, Paragliola R, Ferrari M, et al. (2011) Evaluation of the fracture resistance of reattached incisal fragments using different materials and techniques. Dent Traumatol 27(1): 15-18.

13. Correa MB, Schuch HS, Collares K, Torriani DD, Hallal PC, et al. (2010) Survey on the occurrence of dental trauma and preventing strategies among Brazilian professional soccer players. J Appl Oral Sci 18(6): 572576.

14. Yousef M (2015) Reattachment of fractured teeth fragments in mandibular incisors: a case report. Int Med Case Rep J 8: 87-91.

Your next submission with Juniper Publishers will reach you the below assets

- Quality Editorial service

- Swift Peer Review

- Reprints availability

- E-prints Service

- Manuscript Podcast for convenient understanding

- Global attainment for your research

- Manuscript accessibility in different formats

( Pdf, E-pub, Full Text, Audio)

- Unceasing customer service

Track the below URL for one-step submission

https://juniperpublishers.com/online-submission.php 